\title{
Low-Clearance Truck's Vertical Requirements at Roundabouts
}

\author{
Ranjit Prasad Godavarthy' ${ }^{1}$, Eugene R. Russell ${ }^{2}$ \\ ${ }^{1}$ Upper Great Plains Transportation Institute, North Dakota State University, Fargo, USA \\ ${ }^{2}$ Department of Civil Engineering, Kansas State University, Manhattan, USA \\ Email: ranjit228@gmail.com, geno@ksu.edu
}

Received 14 August 2015; accepted 10 October 2015; published 13 October 2015

Copyright (C) 2015 by authors and Scientific Research Publishing Inc.

This work is licensed under the Creative Commons Attribution International License (CC BY). http://creativecommons.org/licenses/by/4.0/

(c) ()

\section{Abstract}

While roundabouts have already been proven to be an effective intersection treatment, there are many instances where low-clearance vehicles have problems using roundabouts. Low-clearance vehicles, such as lowboy trailer trucks, have problems, damaging the curbs and truck aprons at roundabouts when there is not sufficient ground clearance. This area has been generally neglected by designers and U.S. states. The latest roundabout manual has guidelines available to design various features of the roundabouts, but they are not specific for low-clearance vehicles. While some previous studies have identified roundabout locations with ground-clearance problems for lowboy trailers that have truck-apron heights that are greater than three inches, no published information is available about truck-apron heights based on three-dimensional analyses. This study addresses the ground-clearance problems for low-clearance vehicles at roundabouts by proposing a procedure where truck-apron heights, truck-apron slope, circulatory roadway slope, and approach roadway slope are analyzed to determine the optimum design measurements for a roundabout's vertical profile in order to accommodate low-clearance vehicles without terrain conflict. The study procedure was demonstrated on standard single-lane roundabouts and double-lane roundabouts designed according to latest roundabout guide, and recommendations were provided for truck-apron heights and the grade for various features of the roundabouts. This research can guide transportation planners and decision makers when determining the optimum roundabout vertical-profile design when low-clearance vehicles are expected. The study uses TORUS software to design roundabouts, and the AUTOTURN and AUTOTURN Pro 3D software for generating two-dimensional and three-dimensional vehicle simulations as well as for conducting three-dimensional vehicle-clearance analysis.

\section{Keywords}

Vehicle-Clearance Analysis, Truck Hang-Up Problems, Truck Apron Height, Swept Path Analysis 


\section{Introduction}

It has been well documented that roundabouts can offer several safety and operational benefits over signalized and stop-controlled intersection alternatives. However, the growing use of roundabouts and their benefits could be greatly diminished because they may not be suited for low-clearance vehicles and large trucks. Low-clearance vehicles, such as lowboy trailer trucks, have serious ground-clearance problems at roundabouts, scraping and damaging the truck aprons and curbs. Often, these lowboy vehicles are larger than the roundabout's design vehicle (largest vehicle likely to use the roundabout); therefore, when these vehicles are expected, the geometric design of the roundabout will have to be modified by adding more truck-apron area. Lowboy trailers generally have six to eight-inch clearance, and the latest Federal Highway Administration (FHWA) roundabout guide recommends reviewing the truck apron's vertical design for any vehicle-terrain conflict [1].

Truck aprons in roundabouts are constructed to provide an additional paved area to accommodate off-tracking of large vehicles [2]. A center-island truck apron and an outer truck apron (also referred to as an external truck apron) are two different types of truck aprons [2]. Center-island truck aprons are almost always included in a roundabout design for off-tracking of design vehicle, and outer truck aprons may be needed in restricted intersection geometry or when trucks larger than the design vehicle are expected. A center-island truck apron is a traversable portion of the center island, and an outer truck apron is a traversable portion between two adjacent legs of a roundabout [2]. The truck apron's width is determined based on the swept-path analysis of the design vehicle for the roundabout [1]. Research conducted at Kansas State University has studied the accommodation of oversize/overweight vehicles at roundabouts and summarized that, when vehicles larger than roundabout's design vehicle are expected to use the roundabout, there is a need to construct additional width for the centerisland truck apron and the outer truck apron [3] [4]. Further, the researchers have summarized that large trucks (oversize/overweight vehicles) that utilize the roundabout infrequently must not be considered as design vehicles because they would result in excessive dimensions for the roundabout, decreasing the safety benefits for a majority of the road users [4].

Truck aprons are generally raised four inches above the circulatory roadway to discourage passenger vehicles from using them. Lowboy vehicles generally have a low-clearance and have problems with damaging the curbs and roundabout truck aprons when there is not sufficient ground clearance. In this situation, it is just not about the ground clearance of the lowboy vehicle, but the problem is caused due to the combination of the vehicle's ground clearance, the truck-apron height, the truck-apron slope, the circulatory roadway slope, curbs, and the outer truck apron. Russell, Landman, and Godavarthy [3] have conducted surveys with state departments of transportation (DOTs) and U.S. trucking agencies to study the issues that large trucks have at roundabouts, concluding that the vertical ground-clearance problem for low ground-clearance (lowboy) vehicles is the number one concern from state DOTs and the trucking industry. Further, a survey of state DOTs has shown that lowboy vehicles have problems with curbs and truck aprons which are more than three inches high [3]. The Wisconsin Department of Transportation has determined that various components in a roundabout design impact the ability to move lowboy vehicles: truck-apron width, truck-apron slope, the curb and gutter design between the circulating roadway and the truck apron, and possibly the roadway crown [4]. According to the latest roundabout guide, the cross slope for a circulatory roadway for single-lane roundabouts is generally $2 \%$ away from the center island, and the cross slope for the circulatory roadway for a multi-lane roundabout is in the range of $1.5 \%$ to $3 \%$ away from the center island [1]. Further, the latest roundabout guide recommends a maximum of $2 \%$ cross slope away from the center island for truck aprons because greater slopes can cause loss-of-load incidents [1].

A study conducted by Gingrich and Waddell [5] found that, when there was a choice, most semis and large, single-unit trucks did not use the truck apron during the peak hour and that the smaller vehicles beside the trucks either accelerated or applied the brakes to avoid being at the truck's side. A motor-carrier perspective study about accommodating large trucks at roundabouts has concluded that more education is needed for passengervehicle drivers so that they know how to interact with large trucks at roundabouts; there is also a great need to better design roundabouts for large trucks [6].

There are no available studies which provide recommendations for a roundabout's vertical-profile design geometrics to address the ground-clearance problems for low-clearance vehicles. This area has been neglected by designers and states except for one recent study by the Wisconsin DOT to check the roundabouts on its designated oversize/overweight routes for any ground-clearance problems [4]. The Wisconsin DOT study does not recommend a truck-apron height, approach roadway slopes, or circulatory roadway slopes for single-lane and 
double-lane roundabouts [4].

\section{Objective}

The main objective of the study is to check the ground clearance for the most commonly seen lowboy vehicle at a standard (as specified in the latest roundabout guide, National Cooperative Highway Research Program (NCHRP) 672) single-lane roundabout and a standard double-lane roundabout, thereby providing roundabout vertical-profile design guidelines for solving low-clearance vehicle terrain conflict problems at roundabouts. Also, based on the vehicle-clearance analysis, recommendations for truck-apron heights at these standard roundabouts are provided to plan for expected lowboy vehicles.

\section{Study Methodology}

Based on the design specifications from the latest roundabout guide [1], a standard single-lane roundabout and a double-lane roundabout were designed using TORUS software, assuming a design vehicle of WB-67 (Vehicle length $=73.50 \mathrm{ft}$. and wheelbase $=19.50 \mathrm{ft}$.; American Association of State Highway and Transportation Officials [7]). These two standard roundabouts were assumed to expect lowboy vehicles randomly; therefore, these roundabout designs were considered for design modifications to accommodate a lowboy vehicle. The two standard roundabout designs will be modified with an additional center-island truck apron and an outer truck apron to accommodate a specific lowboy vehicle which is larger than the design vehicle. Later, all possible iterations of the vertical profile designs for these two modified standard roundabouts will be designed three dimensionally using the TORUS software by utilizing several truck-apron heights and grading slopes for various features of the roundabouts, such as, truck apron, circulatory roadway, approach roadway, and exit roadway. Using the vertical-clearance analysis feature of the AutoTURN Pro 3D software, the ground clearance of the selected lowboy vehicle will be checked three dimensionally at each iteration of a roundabout's design; the feature will identify any ground-clearance problems for the bottom of the lowboy vehicle interacting with the truck apron while negotiating a roundabout.

\subsection{Low-Clearance Truck Used for the Study: Wisconsin DOT Lowboy Vehicle}

In order to conduct a vehicle-clearance analysis at a roundabout to recommend truck-apron height and other vertical design features, a lowboy vehicle with horizontal (length, wheelbase, etc.) and vertical (height) dimensions is needed for use in the AutoTURN Pro 3D software utilized with this study. The AutoTURN Pro 3D software's vehicle library has standard AASHTO vehicles but does not include any lowboy vehicles. Therefore, a lowboy vehicle from the Wisconsin DOT vehicle library, "DST lowboy," is used for this study. This vehicle is a threepart vehicle with a tractor (front part of the vehicle), jeep (middle part of the vehicle), and the lowboy (rear part of the vehicle) as shown in Figure 1; the total length is $124.45 \mathrm{ft}$. The actual low-clearance of the DST lowboy is six inches [2]. However, other aspects, such as construction tolerance, the variable path chosen by different truck drivers, drainage grate location, and airbag pressure to keep the vertical clearance that the deck is supposed to have, warrant having a margin of error, and the Wisconsin DOT set one-inch as the margin of error, thus having a five-inch vertical clearance [2]. To implement a similar study in any U.S. state, the first step would be to verify that the Wisconsin DOT DST lowboy is applicable to that state; if not, the researchers need to develop a similar test vehicle that represents the most critical dimensions for the state's lowboys.

\subsection{Single Lane Roundabout: Ground-Clearance Analysis}

A symmetric, single-lane roundabout with an inscribed circle diameter (ICD) of $180 \mathrm{ft}$. (part A of Figure 2) was created using design vehicle WB-67 (vehicle length $=73.5 \mathrm{ft}$. $(22.41 \mathrm{~m})$ ) in the TORUS software and is shown in part A of Figure 2 which has an initial center-island truck-apron width of $21.72 \mathrm{ft}$. The roundabout design is kept simple and symmetric to illustrate the procedure that is adapted in the study. Because the length of the DST lowboy vehicle is greater than WB-67, the roundabout design was modified to accommodate the left-turn, through, and right-turn maneuvers of the DST lowboy from all approaches. Parts A and B of Figure 2 illustrate the additional space requirements of the DST lowboy vehicle for off-tracking beyond the roundabout design for a sample left-turn and through movement swept path simulations at the designed single-lane roundabout. The left-turn movement and through-movement simulations were generated in AutoTURN software in such a way 


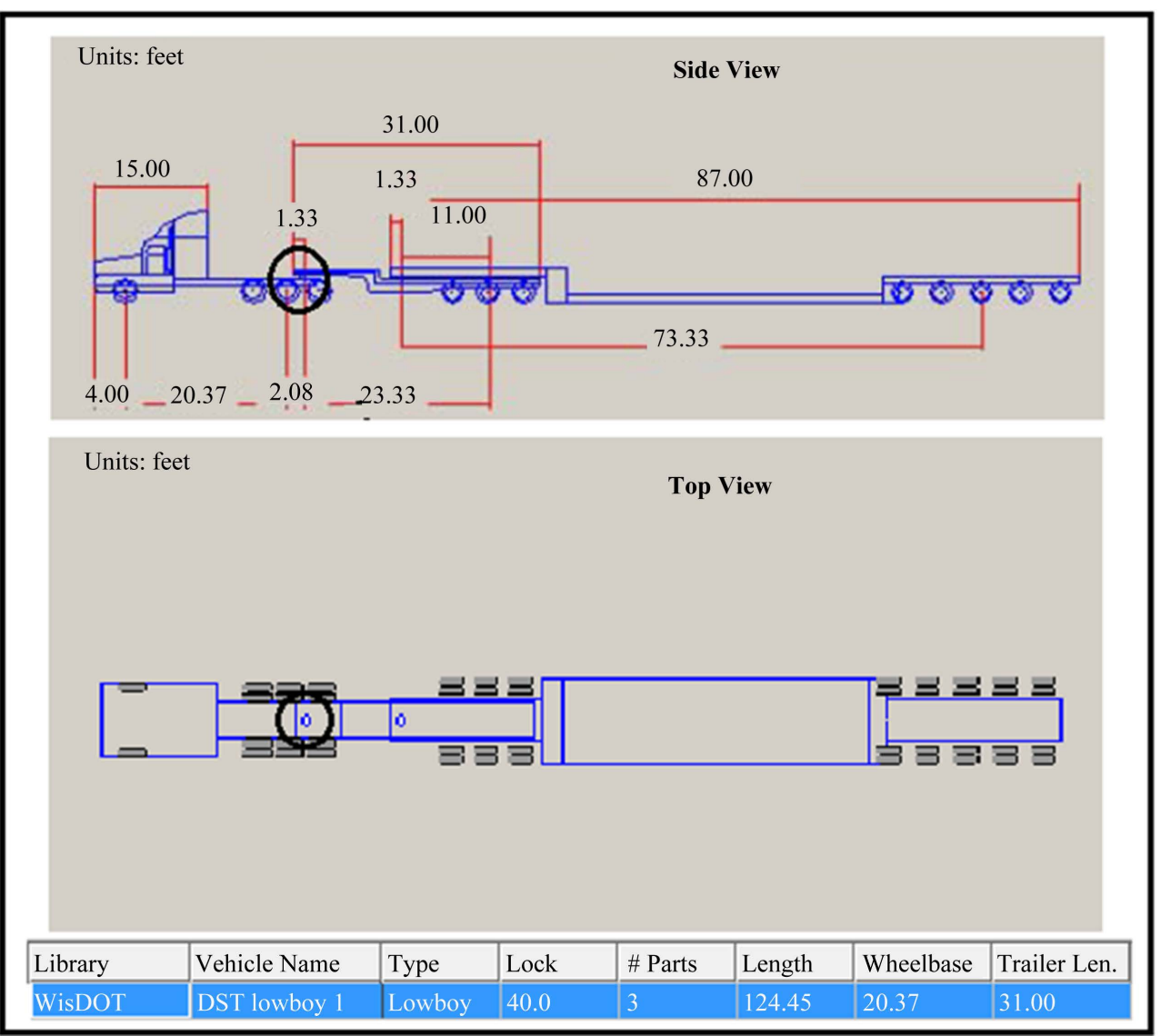

Figure 1. DST lowboy vehicle from the Wisconsin DOT vehicle library.

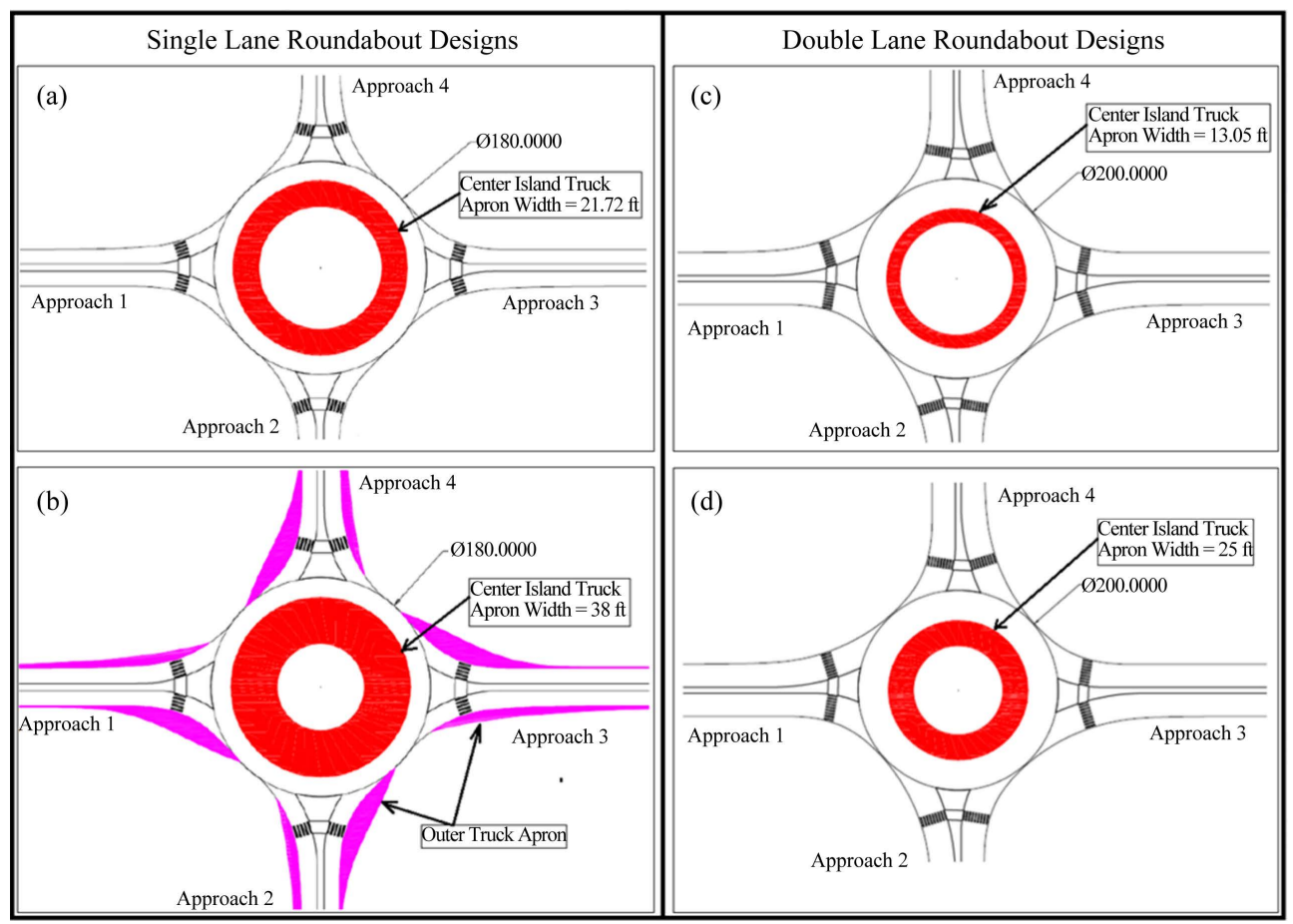

Figure 2. Single-lane and double-lane roundabout designs. 
that the DST lowboy's front tractor is assumed to enter the roundabout in its lane, staying in its lane while circulating the roundabout, and the truck apron is suggested for additional space requirements based on the vehicle's rear-tire tracks. Part B of Figure 2 shows a modified design for the single-lane roundabout with a custom center-island truck apron and an external truck apron that is needed to accommodate a DST lowboy vehicle.

Grading was designed for the modified single-lane roundabout design in the TORUS software with various combinations of truck-apron height, truck-apron cross slope, circulatory roadway cross slope, approach roadway slope (away from the roundabout and towards the roundabout) to check all possible combinations for designing a roundabout terrain that can accommodate a DST lowboy vehicle without ground-clearance problems. While some previous studies identified ground-clearance problems for lowboy vehicles at certain roundabout locations with truck-apron heights more than three inches, no published information was available about optimum truck-apron heights based on three-dimensional analyses. Therefore, truck-apron heights of four inches, three inches, and two inches were considered to check for any ground-clearance problems with DST lowboy vehicles at the designed single-lane roundabout.

According to the latest roundabout guide, a $2 \%$ maximum truck-apron cross slope can be designed for water to drain towards the circulatory roadway [1]. Similarly, a $2 \%$ maximum circulatory roadway cross slope, sloping away from the center island, can be used [1]. Therefore, truck-apron cross slopes of $2 \%, 1.5 \%$, and $1 \%$ sloping towards the circulatory roadway were considered for analysis; similarly, circulatory roadway cross slopes of $2 \%$, $1.5 \%$, and $1 \%$ sloping away from the center island were considered for analysis. Parts A and B of Figure 3 illustrate an example truck-apron slope towards the circulatory roadway and an example circulatory roadway slope away from the center island, respectively. To design the approach roadway slope for all four legs of the roundabout, approach roadway slopes away from the roundabout, such as $3 \%, 2 \%$, and $1 \%$, and approach roadway slopes towards the roundabout, such as $3 \%, 2 \%$, and $1 \%$, were considered. Part A of Figure 3 shows an example roundabout profile for an approach roadway slope towards the roundabout, and part B of Figure 3 shows an example roundabout profile for an approach roadway slope away from the roundabout. The profile of the roundabout can be visualized if a cut were made across the center line of approaches 1 and 3, or approaches 2 and 4 , because the roundabout grading was designed symmetrically for the analysis.

At the modified single-lane roundabout (part B of Figure 2), for each combination of truck-apron height, truck-apron slope, circulatory roadway slope, and approach roadways slopes, a three-dimensional vehicle simulation of the DST lowboy vehicle was generated for left-turn movement and through movement using the $\mathrm{Au}-$ toTURN Pro 3D software. Each three-dimensional simulation was considered for vehicle-clearance analysis using the AutoTURN Pro 3D software to observe any ground-clearance problems with the designed roundabout

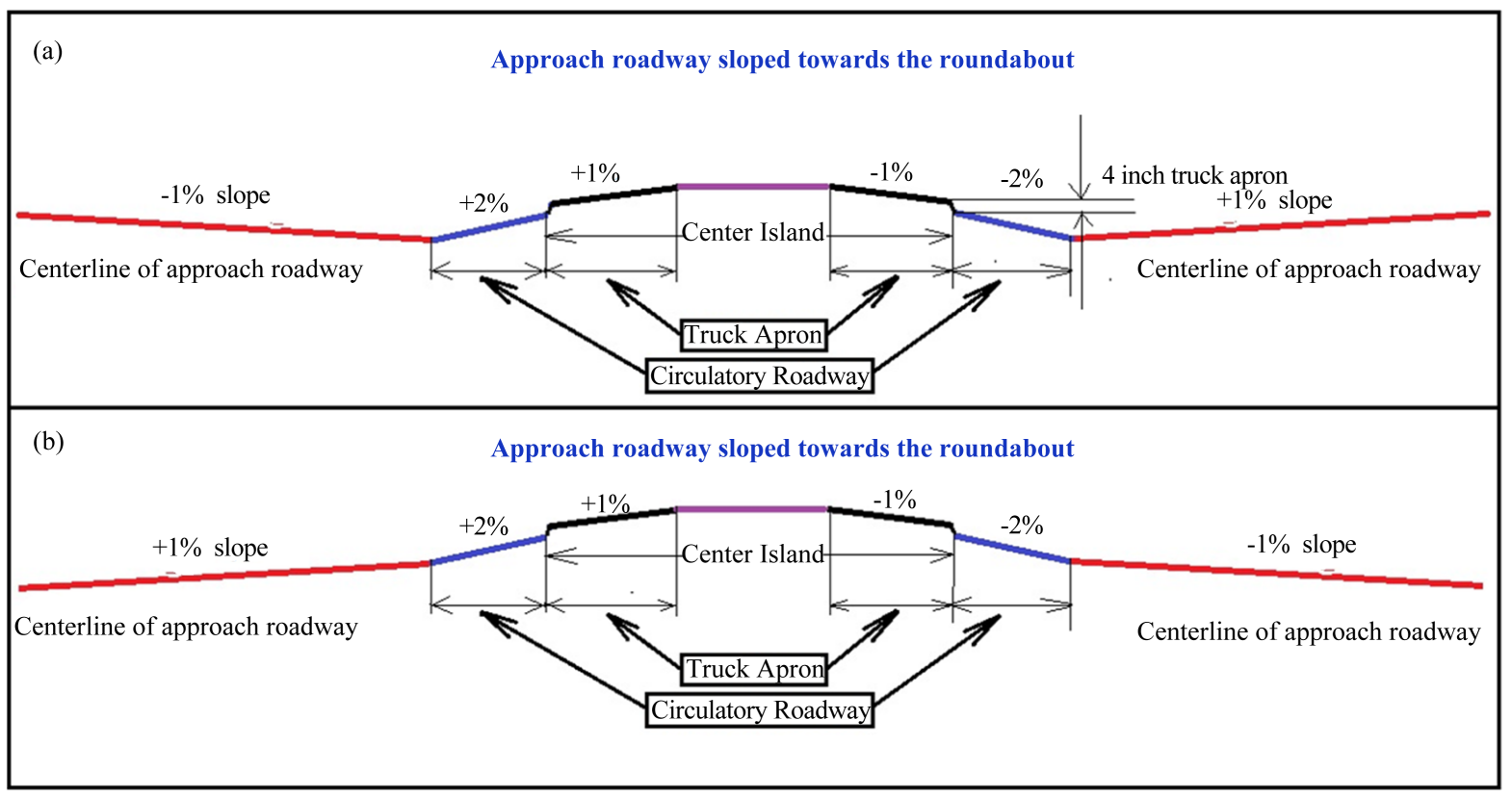

Figure 3. Example grading illustration for a roundabout. 
terrain (specifically the truck apron). Further, the interaction of the vehicle body with the roundabout terrain (specifically the truck apron) was checked at different parts of the lowboy vehicle's body bottom, such as the vehicle centerline path, the center of the rear-axle group, the center of the swept path, the left side of the swept path, and the right side of the swept path.

From Figure 4, it can be observed that the center part of the three-dimensional, left-turn simulation of the DST lowboy vehicle is highlighted in red by the AutoTURN Pro 3D software, warning that a ground-clearance problem was detected. Based on the vehicle-clearance analysis of the DST lowboy vehicle for all possible combinations of truck-apron height, truck-apron cross slope, circulatory roadway cross slope, and approach roadway slope, it was understood that neither a four-inch truck apron height nor a three-inch truck apron height was suitable to accommodate the Wisconsin DOT's DST lowboy vehicle at a symmetric, single-lane roundabout because ground-clearance problems were observed. However, a two-inch truck-apron height can be used for the single-lane roundabout that was considered to accommodate a DST lowboy vehicle, without ground-clearance problems, when the cross slope of the circulatory roadway was not more than $1.5 \%$ away from the center island; when the cross slope of the truck apron was not more than $2 \%$ towards the circulatory roadway; and when the slope of the approach roadway was not more than $3 \%$ either towards the roundabout or away from the roundabout.

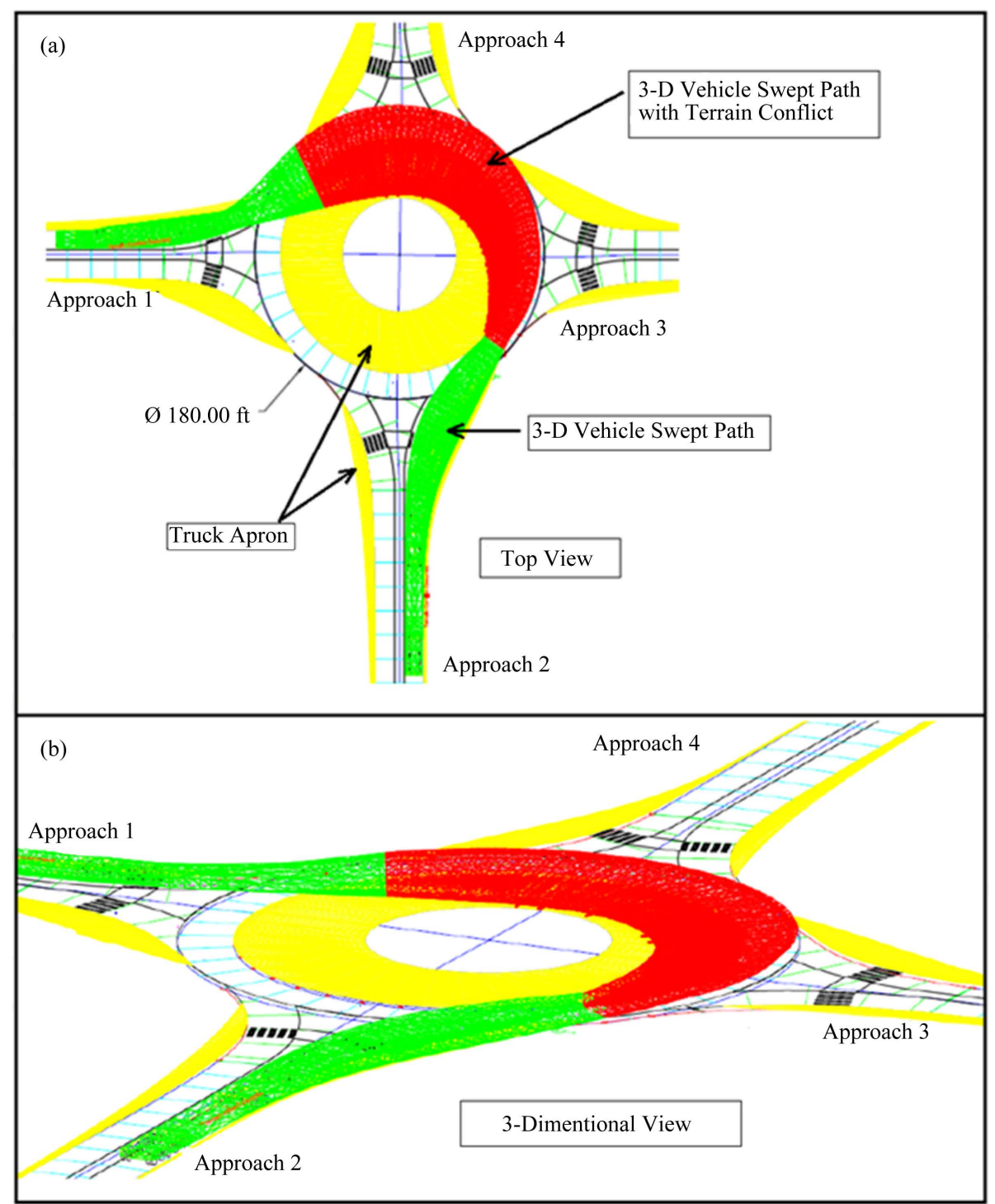

Figure 4. Three-dimensional simulation of the DST lowboy vehicle. 
The results are applicable for a symmetric, single-lane roundabout with an ICD of $180 \mathrm{ft}$. that is designed with a WB-67 design vehicle and is graded according to guidelines provided in the latest FHWA roundabout guide [1]. These recommendations may or may not be applicable for other single-lane roundabouts with varying ICDs, horizontal and vertical design specifications, and design vehicles, but other roundabout designs should be checked with the AutoTURN Pro 3D (or similar) software for their ground clearance in order to validate their design. One limitation of the TORUS software is that it can design the grading needed for various features of the roundabout but not the grading for an external truck apron. Therefore, TORUS assumes that the external truck apron is flat starting from the place the grading was terminated (the end of the circulatory roadway); meaning that TORUS assumes that the external truck apron is not raised above the roadway and that it has a $0 \%$ cross slope. It can be observed from parts A and B of Figure 5 that the rear tires of the DST lowboy use the external truck apron while entering and exiting the roundabout; therefore, grading the external truck apron is also required for precise vehicle-clearance analysis results and for making reliable recommendations. While the analysis' truck-apron height and grading-feature recommendations for the single-lane roundabout may not be reliable, the procedures used in this study serve as a guide that can be followed to conduct ground-clearance analysis in order to determine the truck-apron height for any single-lane roundabout that expects lowboy vehicles with upcoming versions of the roundabout-designing software.

\subsection{Double-Lane Roundabout: Ground-Clearance Analysis}

A symmetric, double-lane roundabout with an ICD of $200 \mathrm{ft}$. was designed using a design vehicle (WB-67) in

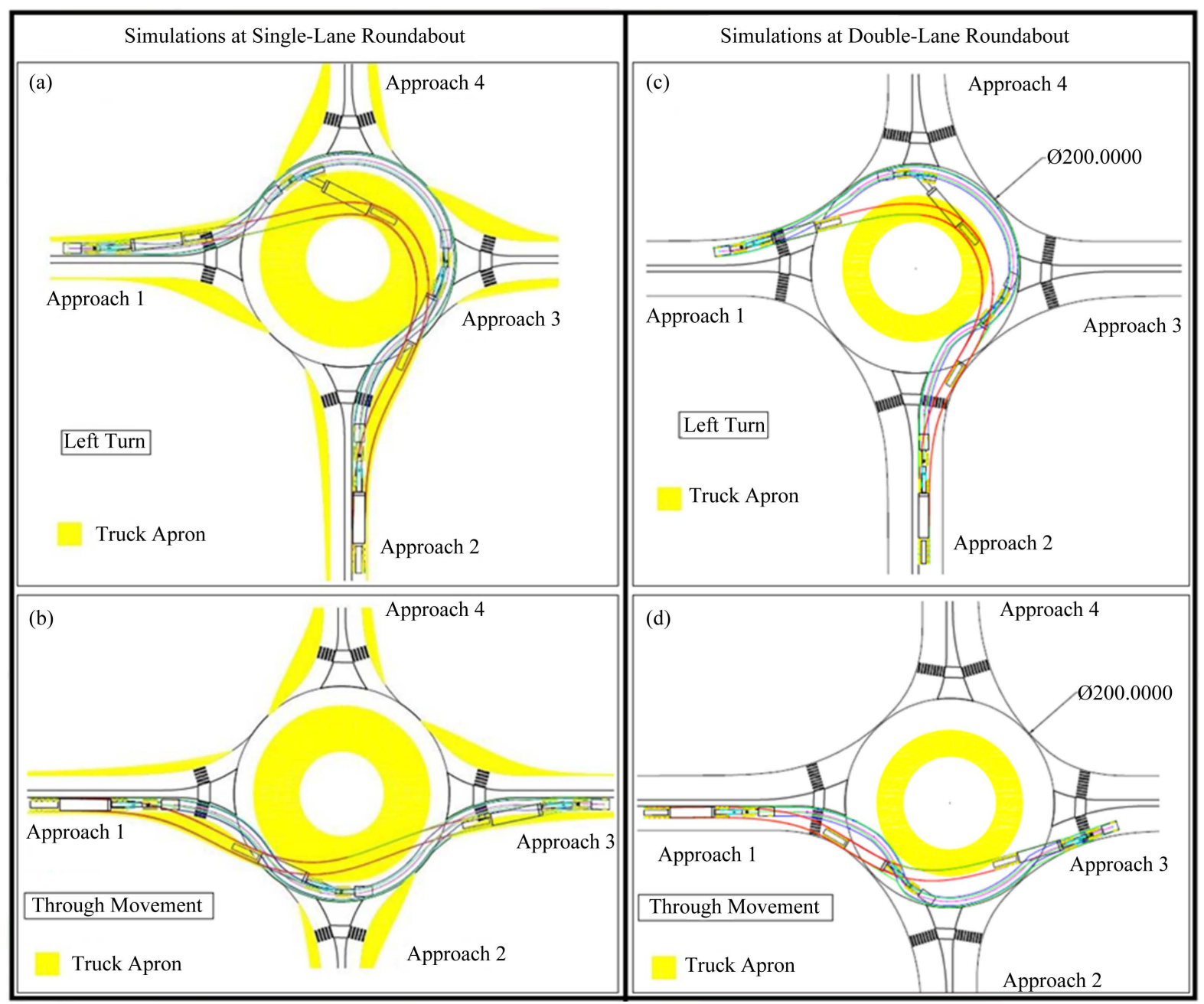

Figure 5. Two-dimensional left- and through-movement simulation for a DST lowboy vehicle. 
the TORUS software; this roundabout is shown in part C of Figure 2 which has an initial center-island truckapron width of $13.05 \mathrm{ft}$. The TORUS software version used for this study did not have the capability to construct lane markings for multi-lane roundabouts; therefore, the double-lane roundabout design in part C of Figure 2 does not have lane markings to identify the number of entering lanes, exiting lanes, and circulating lanes. However, this roundabout has two entering lanes and two exiting lanes for all the approaches, and two lanes in the circulatory roadway.

This roundabout design was modified to accommodate the DST lowboy vehicle's left-turn movement and through movement from all approaches as shown in parts $\mathrm{C}$ and $\mathrm{D}$ of Figure 5. While modifying the doublelane roundabout in part C of Figure 2 to accommodate various movements of the DST lowboy, each vehicle simulation was conducted in such a way that the vehicle enters from either of the two lanes, circulates in either lane, and exits into either lane in order to reduce the need for a center-island truck apron and an outer truck apron. The modified double-lane roundabout (part D of Figure 2) had a custom center-island truck-apron width of $25 \mathrm{ft}$., and it was observed that there was no need for an outer truck apron to accommodate left-turn and through movements of the DST lowboy from any approach.

Grading was designed for the modified double-lane roundabout in the TORUS software; various combinations of truck-apron heights (four inches, three inches, and two inches), truck-apron cross slopes (2\%, $1.5 \%$, and $1 \%)$, circulatory roadway cross slopes $(3 \%, 2.5 \%, 2 \%, 1.5 \%$, and $1 \%$ ), and approach roadway slopes (away from the roundabout and towards the roundabout; $3 \%, 2 \%$, and $1 \%$ ) were utilized to check all combinations that work best for the DST lowboy without having ground-clearance problems. Vehicle-clearance analysis was conducted for each combination of truck-apron height, truck-apron slope, circulatory roadway slope, and approach-roadway slope. Based on the vehicle-clearance analysis at the symmetric, double-lane roundabout, it was concluded that a four-inch truck-apron height was not suitable to accommodate a DST lowboy vehicle at a symmetric, double-lane roundabout that was designed and graded according to guidelines provided in NCHRP report 672 because serious ground-clearance problems were observed. However, a three-inch truck-apron height can be used with the considered double-lane roundabout to accommodate a DST lowboy vehicle with no ground-clearance problems when the cross slope of the circulatory roadway is not more than $2 \%$ away from the center island and when the cross slope of the truck apron is not more than $2 \%$ towards the circulatory roadway. For these recommendations, approach-roadway slopes of $1 \%, 2 \%$, or $3 \%$, towards the roundabout or away from the roundabout, can be used. These recommendations may or may not be applicable to other double-lane roundabouts with varying ICDs and other design vehicles, but the roundabouts should be checked in the AutoTURN Pro 3D (or similar) software for ground-clearance analysis to validate the results.

\section{Conclusions and Recommendations}

Using a three-dimensional analysis, this study addressed the ground-clearance problems for low-clearance vehicles at roundabouts that often have hang-up problems. A study methodology was developed to determine the ideal truck-apron height and roundabout terrain's design specifications when low-clearance vehicles were expected. A Wisconsin-DOT-developed DST lowboy, specified to represent the typical low ground-clearance vehicle (often referred to as "lowboys") that often "hangs up" on roundabouts, was used in this study to analyze various truck-apron heights for single-lane and double-lane roundabouts to check the ground clearance of the DST lowboy at the roundabouts that were designed and graded by following the guidelines in the FHWA roundabout guide (NCHRP Report 672). Software such TORUS, AUTOTURN, and AUTOTURN Pro 3D was used in this study to design the roundabouts and to conduct 3D swept-path simulations in order to understand the terrain conflicts for the DST lowboy vehicle at roundabouts.

Based on the vehicle-clearance analysis, it was concluded that four-inch and three-inch truck-apron heights were not suitable for accommodating the DST lowboy vehicle at the designed symmetric, single-lane roundabout because terrain conflict was observed. A two-inch truck-apron height was suitable for the designed singlelane roundabout to accommodate the DST lowboy vehicle without ground-clearance problems when the cross slope of the circulatory roadway was not more than $1.5 \%$ away from the center island and when the cross slope of the truck apron was not more than $2 \%$ towards the circulatory roadway. For these recommendations, approach-roadway slopes of $1 \%, 2 \%$, or $3 \%$, towards the roundabout or away from the roundabout, can be used. However, these values should be recalculated by following a similar procedure with the next version of the TORUS software or other roundabout design software because the TORUS version used for this study does not 
have the capability to design the external truck-apron width or grade, which could question the reliability of observed results. Also, other states should verify if the Wisconsin DOT DST lowboy vehicle is the typical low ground-clearance vehicle in their state. Similarly, for double-lane roundabouts, it was concluded that a four-inch truck-apron height was not suitable to accommodate a DST lowboy vehicle. A three-inch truck-apron height was suitable for double-lane roundabouts to accommodate the DST lowboy vehicle without ground-clearance problems when the cross slope of the circulatory roadway was not more than $2 \%$ away from the center island and when the cross slope of the truck apron was not more than $2 \%$ towards the circulatory roadway. For these recommendations, approach-roadway slopes of $1 \%, 2 \%$, or $3 \%$, towards the roundabout or away from the roundabout, were used.

The TORUS software used for the study cannot design the height and grade for the external truck apron for a roundabout; therefore, the truck-apron height and terrain-grade recommendations given for a symmetric, singlelane roundabout may not be precise and would have to be validated for site-specific conditions with updated software versions. However, the truck-apron height and grading recommendations for symmetric, double-lane roundabouts described in the study are reliable because the double-lane roundabout does not need an external truck apron to accommodate the study's DST lowboy. While some of the study's results and recommendations are precise and reliable, the procedures used in this study serve as guidelines that can be followed to conduct ground-clearance analysis in order to determine truck-apron height and roundabout-terrain grade for any roundabout that expects a lowboy vehicle.

\section{Acknowledgements}

The authors would like to acknowledge Patrick Fleming, Wisconsin DOT, for sending a great deal of important material, including the DST lowboy vehicle file that was directly related to the study's objectives.

\section{References}

[1] Rodegerdts, L., Bansen, J., Tiesler, C., Knudsen, J., Myers, E., Johnson, M., Moule, M., Persaud, B., Lyon, C., Hallmark, S., Isebrands, H., Crown, R.B., Guichet, B. and O’Brien, A. (2010) Roundabouts: An Informational GuideSecond Edition. NCHRP Report 672, Transportation Research Board of the National Academics, Washington DC.

[2] Godavarthy, R.P. (2012) Network and Design Concepts for Accommodating Large Trucks at Roundabouts. Ph.D. Dissertation, Kansas State University, Manhattan.

[3] Russell, E.R., Landman, D. and Godavarthy, R.P. (2013) A Study of Accommodating Oversize Overweight Vehicles (OSOW) at Roundabouts. Transportation Research Board Annual Meeting: Compendium of Papers, Washington DC.

[4] Russell, E.R., Landman, D. and Godavarthy, R.P. (2013) Accommodating Oversize Overweight Vehicles at Roundabouts. Report No. K-TRAN: KSU-10-1, Kansas Department of Transportation.

[5] Gingrich, M. and Waddell, E. (2008) Accommodating Trucks in Single and Multilane Roundabouts. Transportation Research Board, National Roundabout Conference, Kansas City, 18-12 May 2008.

[6] Park, L. and Pierce, D. (2013) Accommodation of Large Trucks in Roundabouts: Motor Carrier Perspective. Transportation Research Record: Journal of the Transportation Research Board, 2388, 10-13. http://dx.doi.org/10.3141/2388-02

[7] American Association of State Highway and Transportation Officials (2004) A Policy on Geometric Design of Highways and Streets. 